\title{
Wasp bite related myocarditis: a rare manifestation
}

\author{
S Kaushal ${ }^{*}$, S Singh ${ }^{2}$ \\ Assistant Professor ${ }^{{ }^{*}}$, Professor and Head ${ }^{2}$, Department of Anaesthesiology and Intensive care, \\ Indira Gandhi Medical College, Shimla, Himachal Pradesh, India.
}

\begin{abstract}
Wasp bite induced allergic reactions or organ dysfunction are not uncommon in tropical countries. Though anaphylaxis and renal dysfunction have been reported, myocardial involvement in the form of myocarditis is rare. Awareness about such complications is important as these affect clinical course and outcomes. We present a case of wasp bite induced myocarditis which was diagnosed when patient did not improve as expected.
\end{abstract}

Keywords: Myocarditis; allergic; wasp bite; renal; toxic; anaphylactic

\section{Introduction}

Wasp bites are a common form of toxic envenomation in tropical countries. ${ }^{1}$ The clinical manifestation can be local or systemic, including anaphylactic reactions. Infrequently, wasp bites lead to serious clinical sequelae like intravascular haemolysis, rhabdomyolysis, thrombocytopaenia, acute kidney injury, liver function impairment, myocardial infarction and myocarditis. ${ }^{2}$

Delays in management increase morbidity and might prove fatal. We present a case of wasp bite associated myocarditis and heart failure, which recovered fully with supportive measures.

\section{Case report}

A 55-year old, previously healthy male adult, was admitted to the Emergency Department of our hospital with a history of multiple wasp bites on head and face $4 \mathrm{hrs}$ prior to admission. In addition to local swelling and pain, he developed progressive difficulty in breathing within an hour of the event. He had received intravenous fluids, adrenaline, steroids and anti-histamines at local hospital before referral to our hospital. He was

*Correspondence: S Kaushal

E mail: sonalikaushal33@gmail.com

iD https://orcid.org/0000-0002-1643-1505

Received: $30 / 08 / 2017$

Accepted: 06/10/2017

DOI: http://doi.org/10.4038/slja.v26i1.8274

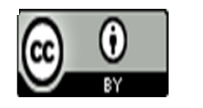

drowsy, and had macroglossia, shortness of breath, and swelling over face. His pulse rate was 112 beats/min, blood pressure was $76 / 45 \mathrm{mmHg}$ and arterial oxygen saturation $\left(\mathrm{SpO}_{2}\right)$ was $48 \%$ at admission. Diffuse wheeze was present in chest on auscultation. He was immediately intubated, and put on artificial ventilation. $\mathrm{He}$ was started on bronchodilators, anti-histamines, steroids and inotropic support (Noradrenaline infusion). His haemoglobin, total leukocyte count, serum urea and serum creatinine were $12.7 \mathrm{~g} / \mathrm{dL}, 16,000 \mathrm{cells} / \mathrm{cu}$ $\mathrm{mm}, 30 \mathrm{mg} / \mathrm{dL}, 1.1 \mathrm{mg} / \mathrm{dL}$, respectively. Arterial blood gas analysis at admission showed metabolic acidosis with severe hypoxaemia. Electrocardiogram showed sinus tachycardia. His serum electrolytes, renal function and liver function tests remained within normal limits. His facial swelling decreased and chest wheeze progressively improved over next $48 \mathrm{hrs}$. However, difficulty in weaning from ventilator and persistent requirement of inotropic support (though decreased as compared to that at admission) even after 48hrs despite improvement in other signs and symptoms prompted detailed cardiovascular evaluation. Bedside echocardiography revealed global hypokinesia of the left ventricle with mildly decreased contractility and LVEF of $45-50 \%$. His qualitative serum troponin $\mathrm{T}$ was negative. Repeat ECG showed sinus tachycardia with non-specific ST/T wave changes. A diagnosis of myocarditis was made. He improved over next $48 \mathrm{hrs}$ with symptomatic support and was off inotropic support after 4 days. He was weaned off ventilator by $6^{\text {th }}$ day and later managed with oral beta blockers, ACE inhibitors and diuretics. Repeat echocardiography at 2 weeks after admission revealed normally 
functioning myocardium with 60-65\% LVEF. He was discharged at 3 weeks after admission in a normal condition without any prescription drugs.

\section{Discussion}

Stinging Apidae (bees) and Vespidae (wasps and hornets) insects belong to the order Hymenoptera and class Insecta. Their venom is a mixture of amines such as mellitin, apamine, phospholipases, hyaluronidases, acid phosphatase, histamine and kinin. ${ }^{3}$ Phospholipase A and surface agent such as mellitin and apamine act on the red cell membrane leading to haemolysis. Coagulopathy has been related to increased level of antithrombin and decreased level of fibrinogen, high molecular weight kininogen, factor $\mathrm{V}$ and VII. Rhabdomylosis is a direct effect of the venom on the muscular tissues. ${ }^{4}$ Other manifestation can be renal failure due to acute tubular necrosis because of hypotension or pigment nephropathy resulting from rhabdomyolysis or intravascular haemolysis, or acute interstitial nephritis. Liver dysfunction in form of centrilobular necrosis can also occur. ${ }^{5}$

Giant Asian honeybee stings can cause myocardial involvement in previously healthy patients. ${ }^{6}$ The characteristic pain of acute cardiac event can be masked by generalized aches and pain due to multiple stings. Kounis Syndrome also known as allergic angina or allergic myocardial infarction characterized by allergic reaction, coronary artery spasm and chest pain can occur in this setting. Direct toxic effects of the venom on myocardium could also be culprits. Also, acute pulmonary oedema can occur secondary to anaphylactoid reaction or left heart failure. ${ }^{7}$

In our patient, treatment of anaphylaxis unmasked myocardial involvement as shock did not improve on expected lines. Tachycardia, non-specific ST/T wave changes on electrocardiogram, signs of heart failure, diffuse myocardial involvement and decreased global LV function suggested a diagnosis of myocarditis. It could be due to diffuse coronary spasm or direct toxic effect of toxins on myocardium. Gradual improvement in symptoms with only supportive management and complete recovery over next 3 weeks are concordant with the diagnosis of myocarditis. As patient never had fever and clinical manifestations associated with wasp bites, common infectious causes of myocarditis were not considered. As our patient received medical attention early and was being managed symptomatically even before arrival at our hospital, other systemic manifestations secondary to anaphylaxis or shock were not observed.

The treatment of wasp bite is timely management of anaphylaxis and supportive therapy for organ related complications e.g. dialysis for acute kidney injury etc. It is likely that individuals with comorbidities would be at higher risk for development of complications. Our case highlights rare myocardial involvement after wasp bite envenomation. It is important to discern this as it might be missed during initial phase because of overlapping signs and symptoms, impairing or delaying usual recovery.

\section{References}

1. Ewan PW. Venom allergy. BMJ 1998;316:1365-8. https://doi.org/10.1136/bmj.316.7141.1365 PMid:9563993 PMCid:PMC1113072

2. Ratnoff OD, Nossel HL. Wasp sting anaphylaxis. Blood 1983;61:132-9. PMid:6336652

3. Golden DB. Stinging insect allergy. Am Fam Physician 2003;67:2541-6. PMid:12825843

4. McGain F, Harrison J, Winkel KD. Wasp sting mortality in Australia. Med J Aust 2000;173:198200.

PMid:11008593

5. Vetter RS, Visscher PK, Camazine S. Mass envenomations by honey bees and wasps. West $\mathbf{J}$ Med 1999;170:223-7. PMid:10344177 PMCid:PMC1305553

6. Ceyhan C, Ercan E, Tekten T, Kirilmaz B, Onder R. Myocardial infarction following a bee sting. Int $\mathrm{J}$ Cardiol 2001;80:251-3. https://doi.org/10.1016/S0167-5273(01)00477-6

7. Portnoy JM, Moffitt JE, Golden DB, et al. Stinging insect hypersensitivity: a practice parameter. The Joint Force on Practice Parameters, the American Academy of Allergy, Asthma and Immunology, the American College of Allergy, Asthma and Immunology, and the Joint Council of Allergy, Asthma and Immunology. J Allergy Clin Immunol 1999;103:963-80. https://doi.org/10.1016/S0091-6749(99)70450-1 